\title{
A Case Report: Hysterectomy in Eleventh Months Infant
}

\author{
SHAMSUN NAHAR ${ }^{1}$, BISHWAJIT DAS $^{2}$, GULSHAN SOFDAR ${ }^{3}$, MRINAL KUMAR SHARKAR $^{4}$
}

\section{Introduction:}

Endometrial carcinoma in an infant is a very rare condition; it typically occurs in elderly patients; approximately $88 \%$ are postmenopausal at the time of diagnosis ${ }^{1}$. Classically, Endometrial carcinoma affects the obese, nulliparous, infertile, hypertensive and diabetic white women, but usually can be occur in the absence of all these factors. Estrogens are implicated as causative factor in endometrial carcinoma because a high incidence of this disease in patients with presumed attention in oestrogen metabolism and in those who take exogenous estrogens. Polycystic ovarian disease and Granulosa cell tumours of the ovary can produce high level of oestrogens but are rare cause of hyperestrogenism and endometrial carcinoma ${ }^{2}$.Gonadal dysgenesis can also be associated with endometrial adenocarcinoma ${ }^{3}$. Embrional vaginal carcinoma are most commonly seen in very young girls. The tumour usually involves the vagina, the cervix may be affected as well, particularly in an older child. Batryoids sarcoma arises from the submucosal tissue and rapidly spread beneath an intact vaginal epithelium and bulges as polypoid growth. Three types of vaginal and cervical tumour may appear during childhood \& early teens, endometrial carcinoma occur most often in young children. Carcinoma arising in a remnant of a mesonephric duct occurs more often in girls of $3 \mathrm{yrs}$ of age or older ${ }^{4}$. Clear cell adenocarcinoma of nulliparous origin often associated with a history of antenatal exposure of DES ( Diethylestilbestrol ). But no clear cut evidence is detected in infant or childhood endometrial carcinoma.

\section{Case note}

An eleventh months baby named Israt came with her parents with history of excessive irregular pervaginal bleeding for last 4 months. At her age of 7 months she had developed scanty recurrent pervaginal bleeding but sometimes excessive. For that region her parents consulted with a Gynaecologist and it was thought that foreign body may be inside of vagina. She was examined under anaesthesia and any vaginal or rectal abnormalities could not be detected. After few days pervaginal bleeding was started which was excessive and persist 3-5 day. It was thought her precocious puberty related to hormone producing tumour in ovary or adrenal gland. She was investigated accordingly to this. Ultrasonography of the whole abdomen detected no ovarian or any other pathology except slight uterine enlargement, measured about $6.6 \times 3.4 \mathrm{~cm}$, and homogeneous myometrial echoes with thickened endometrium.

On Investigation: $\mathrm{Hb} \%$ found to be $8 \mathrm{gm} / \mathrm{dl} \mathrm{ESR}, \mathrm{TC}$, DC, platelet count- normal, Serum. TSH, Prolactin, $\mathrm{FSH}$, LH, Oestrogen \& testosterone were normal, But progesterone was high.

During her bleeding phase some endometrial cast came out which was sent for histopathology. Histopathological report came as endodermal sinus tumour. Estimation of serum á-fetoprotein level showed value - > $5845.00 \mathrm{IU} / \mathrm{ml}$ (normal value is $<10.9 \mathrm{lU} / \mathrm{ml}$ ). Finally total abdominal hysterectomy with right-sided salpingophrectomy was done as a life saving measure.

\section{Operation Note:}

Operation was done on 08/11/09. Abdomen was opened by Pfennenstiel incision and found enlarged uterus more in length. Both ovaries and tubes were healthy. No sign of obvious intraabdominal metastasis observed but all mesentric lymph nodes were prominent. Total abdominal hysterectomy with rightsided salpigo-ophorectomy was done and bleeding

1. Associate Prof. \& Head, O\& G, KMCH

2. Consultant $(\mathrm{O} \& \mathrm{G}), \mathrm{KMCH}$

3. Assistant Prof \& Head Dept. of Path. (NICVD)

4. Asst. Prof. (Oncology), $\mathrm{KMCH}$ 
minimum. Messentic lymph node was taken for histopathological evaluation (picture-2), Abdomen was closed by placing a drain. Cut section of the uterus showing friable, pale, gray, mucoid tissue in which variable amounts of hemorrhagic area and necrosis were present. Uterus and mesenteric lymph node send for histopathological examination. Histopathological report confirmed the diagnosis as endometrial sinus tumour within uterus, no metastasis to the ovary, the lymph nodes showed reactive hyperplasia. Post operative period was unventful.

\section{Follow up report and outcome}

After 15 days from her surgery serum alpha feto-protein was found to be $17 \mathrm{iu} / \mathrm{ml}$ and the baby was well. She was advised to have estimation of serum alpha fetoprotein at 15 days interval but the patient lost from follow up. After 3 months she came with a solid abdominal lump and fever. Serum alpha feto-protein was done which was found again raised to $38700 \mathrm{iu} /$ $\mathrm{ml}$. On x-ray examination lung metastasis was detected. She was advised to start chemotherapy as soon as possible but her parents refused to take chemotherapy. 2 weeks later the baby was died without receiving any further treatment.

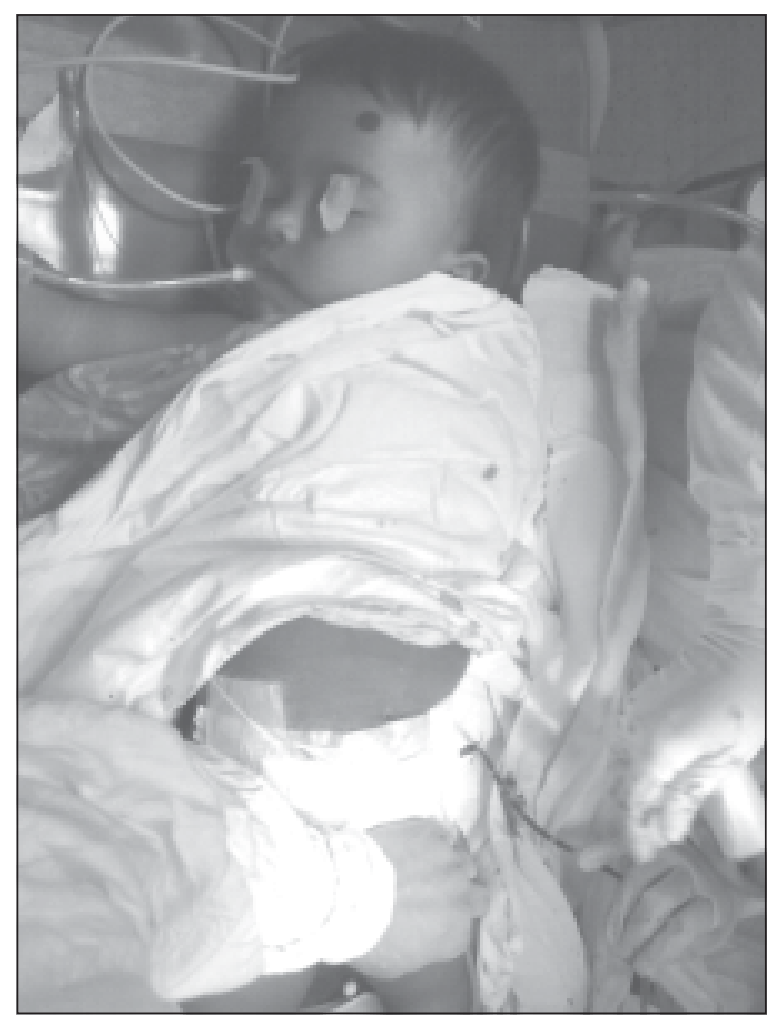

Fig.-1: Baby Israt, 11 months old

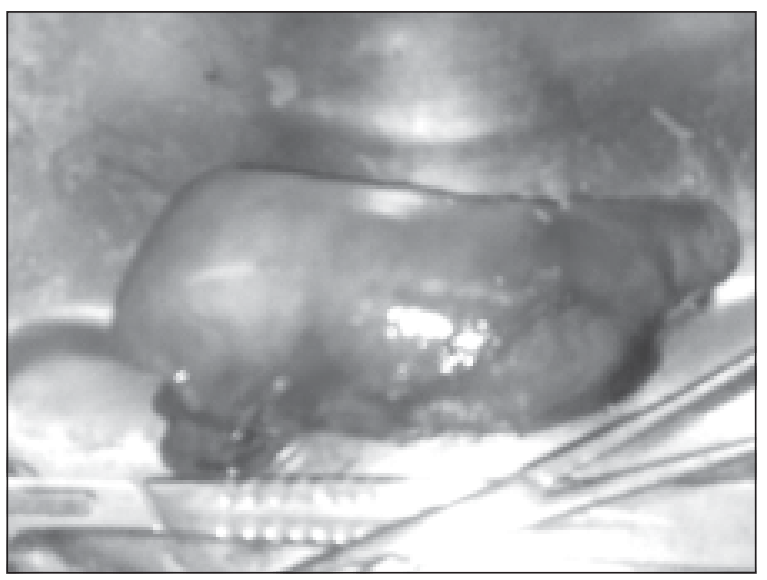

Fig.-2: Total resected uterus with right ovary

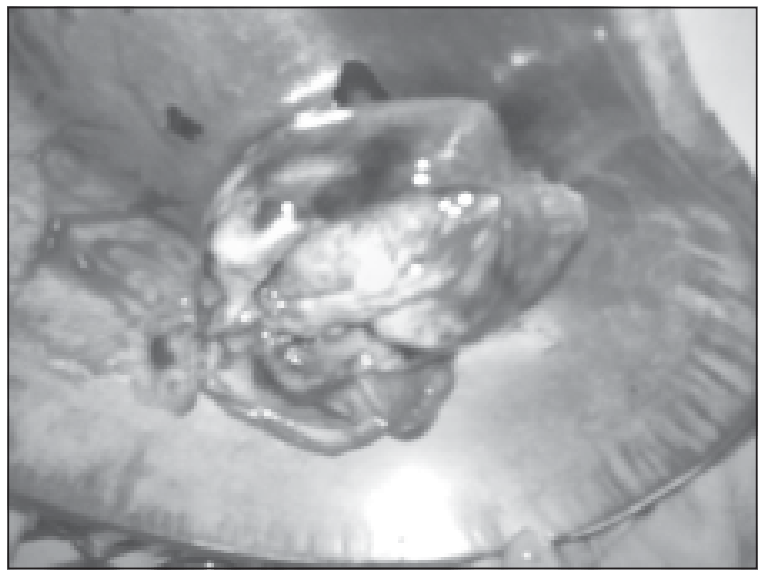

Fig.-3: Cut section of uterus showing thickened endometrium and fleshy polypoidal growth

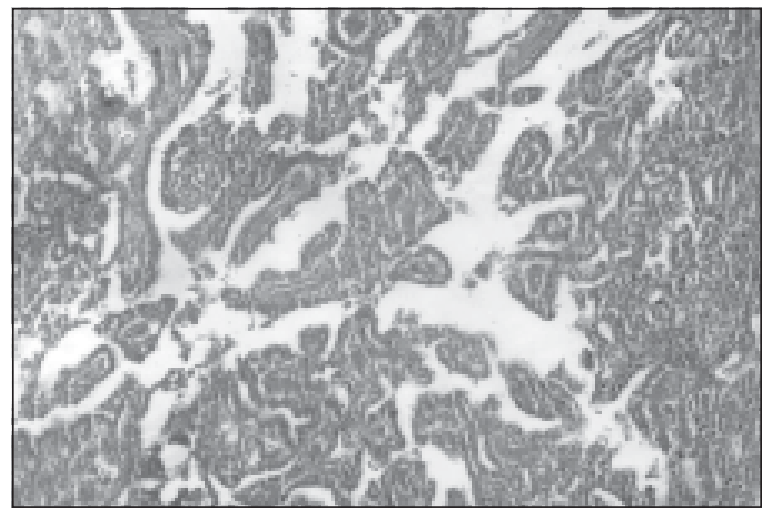

\section{Discussion:}

Regarding infant \& childhood period solely uterine origin of any benign \& malignant tumour are still now not known to us. Genital tract tumour in infant \& childhood are more frequently yolk sac tumours, pure malignant germ cell tumour and are the most common germ cell tumours benign or malignant develops in 
the testes of infants \& young boys and ovaries in girls ${ }^{1}$. But yolk sac tumour is the only malignant germ cell tumour occasionally develops in the sacro-coccygeal region of the infant. Endodermal sinus tumour (yolk sac tumour) typically affects infants under 2 years of age and is more commonly located in either the posterior vaginal wall or fornix ${ }^{5,6}$. It is mainly in ovarian origin. $23 \%$ of the patients were prepubertal at the time of diagnosis. None of the patients presented with precocious puberty, amenorrhaea or hirsuitism. Vaginal bleeding occurred in only $1 \%$. It is thought to be derived from a multipotential embryonic tissue and differentiation toward yolk sac structure ${ }^{7}$. Similar to the yolk sac, the tumour is rich in alpha-fetoprotein and alpha-antitripsin.

Microscopically it appearance is very variable. There are reticular or microcystic areas by loose meshwork lined by flat or cuboidal cell, rounded pseudocapillary process with central vessels (Schiller - Duval bodies) and solid undifferentiated areas (Picture -4). Their chemical composition is heterogerous; they usually stain for Ü-fetoprotein but they may also contain Ü- 1antitropsin basement membrane components (type IV collagen and Laminin). DNA plody studies have shown that these tumors are almost invariably aneuploid ${ }^{8}$. Yolk sac tumour is confused with clear cell adenocarcinoma but immunohistochemically, reactions for alpha-feto protein factors favour yolk sac tumour ${ }^{9}$.

We could not collect any information from the web site or journal about endometrial sinus tumour solely arises from the uterine endometrium. It is an unique case, for that region we interested to present the case.

Most patients are children or young girl presenting with abdominal pain and a rapidly developing pelvic mass. The tumours usually appear do involve a single ovary but grow rapidly and aggressively. These tumour were once almost uniformly fatal within 2 years of diagnosis, but combination chemotherapy has measurably improved the outcome. The actual survival at 3 years of age is only $13 \%$.

In early series most patients with vaginal yolk sac carcinoma had died with generalized metastasis ${ }^{10}$.

After primary surgery in this patient alpha-feto protein come to normal within 15 days but it again raised at high level within one month. We counseled the baby's parent to start chemotherapy. But they refused to take it and after two months a lump was arisen in left side of abdomen with evidence of lung matastesis. She was died after 4 months from initial surgery without receiving any further treatment.

\section{References:}

1. Voigt LF, Weiss NS; Epidemiology of endometrial carcinoma- Cancer treat Res 49, 121, 1989

2. Anant F et al: Endometrial cancer. Lancet 2005; 366 (9484): 491

3. Mc Carty KS Jr. Banton TK, Fetter BF, et al: Correlation of oestrogens \& progesterone receptors with histologic differentiation in endometrial adenocarcinoma. Amj pathol 96: 171-183, 1979

4. Kurman RJ, Norris HJ: Endometrial sinus tumour of the overy. A clinical and pathological analysis of 71 cases. Cancer 38: 2404-2419, 1996.

5. Copeland LJ, Sneige N, Ordonex NG, Hanlack $\mathrm{KC}$ et al; Endodermal sinus tumour in vagina \& cervix, Cancer 55: 2558-2565, 1985)

6. Tavanoli FA, Norris HJ: Smooth muscle tumour of the vagina, Obstel Gynaecol 53: 689-693, 1979.)

7. Van niekerk cc, Boerman OC, Remaekers FC, Poels LG: Marker profile of different phases in the transition of normal human ovarian epithelium to ovarian carcinoma. AMJ pathol 138: 455-463, 1991

8. Kommoss F, Bibbo M, Talerman A: Nuclear deoxyribonuclic acid content (ploidy) of endodermal sinus (yolk sac) tumor. Lab Invest 62: 223-231, 1999

9. Zirker TA, Silva EG, Marris M, Ordonous NG: Immunohistological differentiation of clear cell carcinoma of the female genital tract and endodermal sinus tumour with the age of alphafeto-protein and leu-ML. AMJ clin P) 601-603, 1995.

10. Norris HJ, Bagley GP, Taylon HB: Carcinoma of the infant vagina, A distinctive tumour, Arch pathol 90: 473-479, 1970. 